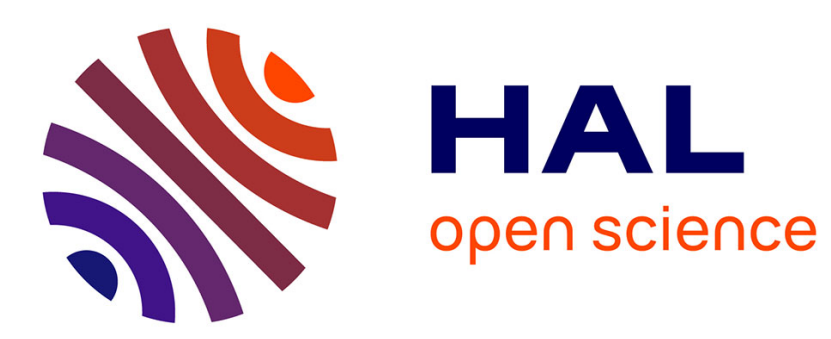

\title{
Concept and processing of buried photomasks
}

\author{
J.P. Panabière, J.M. Francou, Agnès Weill, L. Guérin, P. Moschini, A. Inard, \\ G. Amblard, F. Lalanne
}

\section{To cite this version:}

J.P. Panabière, J.M. Francou, Agnès Weill, L. Guérin, P. Moschini, et al.. Concept and processing of buried photomasks. Revue de Physique Appliquée, 1990, 25 (8), pp.859-865. 10.1051/rphysap:01990002508085900 . jpa-00246247

\section{HAL Id: jpa-00246247 https://hal.science/jpa-00246247}

Submitted on 1 Jan 1990

HAL is a multi-disciplinary open access archive for the deposit and dissemination of scientific research documents, whether they are published or not. The documents may come from teaching and research institutions in France or abroad, or from public or private research centers.
L'archive ouverte pluridisciplinaire HAL, est destinée au dépôt et à la diffusion de documents scientifiques de niveau recherche, publiés ou non, émanant des établissements d'enseignement et de recherche français ou étrangers, des laboratoires publics ou privés. 
Classification

Physics Abstracts

42.90

\title{
Concept and processing of buried photomasks
}

\author{
J. P. Panabière, J. M. Francou, A. Weill, L. Guérin, P. Moschini, A. Inard, G. Amblard and F. Lalanne
}

CNET/CNS, BP98, 38243 Meylan Cedex, France

(Reçu le 30 juin 1989, révisé le 7 décembre 1989, accepté le 11 mai 1990)

\begin{abstract}
Résumé. - Une nouvelle méthode d'élaboration des photomasques est présentée. Au lieu de déposer les motifs géométriques sur la surface du substrat transparent, ceux-ci sont situés au fond de tranchées préalablement gravées dans le substrat transparent. Les tranchées sont définies par lithographie E-beam et gravure plasma RIE. Deux manières de les remplir sont envisagées : planarisation et lift-off. Les différents avantages du masque enterré sont analysés, et notamment la très haute résolution. Enfin ce papier se termine par l'illustration des capacités de transfert d'image d'un tel masque par lithographie en contact sous vide dans les résines novolaques.
\end{abstract}

\begin{abstract}
A new method for fabricating photomasks is proposed. The mask is prepared by burying the absorbent patterns inside the transparent photoplate instead of depositing them on the surface of the photoplate. After imaging and etching trenches into the glass substrate, an absorbent material is set into them. Two different ways of filling in these holes are considered : planarisation and lift-off. Various advantages of this technique are expected, namely high resolution. This paper presents results obtained by vacuum contact printing of positive and negative novolak based photoresists exposed through buried masks.
\end{abstract}

\section{Introduction.}

It is the consensus that optical lithography will dominate semiconductor manufacturing down to $0,5 \mu \mathrm{m}[1]$. Consequently, maskmakers are now wondering what the problems and limitations in maskmaking are, what approach they should adopt in order to overcome the technical difficulties, what trade-offs demand particular attention in the drive towards improved quality and yield. The literature attempts to determine the critical areas in which some progresse should be made in the near future : chrome coating, resist selectivity, dry etching, turnaround, metrology, defect and particulate inspection, mask repair [2,3].

This paper presents a new concept of maskmaking for integrated circuits manufacturers : the buried mask [4 - 7]. The idea of a buried mask is based on the following concept : the absorbing patterns should not lie on a flat transparent surface (classical mask or relief mask) but should be better deposited at the bottom of shallow trenches previously etched into the transparent substrate.

First the mode of fabrication is described. The expected properties of the buried mask are then presented and discussed in relation to the above critical areas. Finally some results obtained using the buried mask are illustrated. It is concluded that engraving the absorbent patterns in glass could open up a new road in photomasking requiring high resolution and/or severe $\mathrm{C} \mathrm{D}$ control, and constitute an interesting tool to respond to the $0.5 \mu \mathrm{m}$ optical lithography challenge, whatever the reduction of the optical system may be (1X or $5 \mathrm{X})$.

In figure 1 are shown the schematical representations of the cross sections of a) a classical mask, or relief mask and b) a buried mask. From this scheme it can be understood that the problem of adhesion between the glass and the pattern is not so crucial in the case of the buried mask as it is in the case of the relief mask. This

a
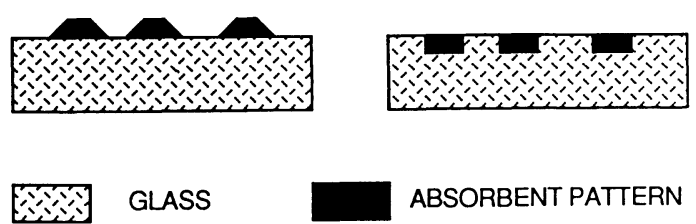

ABSORBENT PATTERN

Fig. 1. - Schematical representations of the cross sections of a) a classical mask, or relief mask and b) a buried mask. 
paper shows therefore that many other materials than $\mathrm{Cr}$ (normally employed because of its high adhesion characteristics when deposited over glass) may constitute the absorbing feature of the mask.

\section{Experimentals.}

2.1 PATTERning THE TRENCHES. - At first, a very thin layer (30-40 nm) of $W$ is deposited by sputtering over the raw photoplate. No detachment due to a loss of adhesion or to the stress effect can be observed. A high resolution resist, $0.2 \mu \mathrm{m}$ of PMMA for example, is then spun onto the plate and exposed $\left(200 \mu \mathrm{Cb} / \mathrm{cm}^{2}\right)$ to the beam of the pattern generator. Owing to the conductive $\mathrm{W}$ layer, no charge effect is observed during exposure. After development (MIBK/IPA, 1:3) of the resist, the image is then transferred by RIE plasma etching into the W layer (SF6, $8 \mathrm{~m}$ Tor, power $60 \mathrm{~W}$, flow rate $15 \mathrm{~cm}^{3}$ ) which acts as a counter-mask during the $150 \mathrm{~nm}$ RIE etching of the glass substrate (CHF3, $100 \mathrm{~m}$ Tor, power $90 \mathrm{~W}$, flow rate $1,2 \mathrm{~cm}^{3}$ ). According to this process the side angle of the trenches approaches the $90^{\circ}$ value. No roughness can be detected on the surface of the glassplate even when subjected to plasma for several minutes. A fused quartz substrate is well adapted to being recessed as it reacts to the etch process like $\mathrm{SiO}_{2}$.

According to our RIE plasma etching experiments, quartzplates appear to be very much easier to handle than borosilicate glassplates. As quartz has an extremely low thermal expansion coefficient and is fully transparent down to wavelengths below $200 \mathrm{~nm}$ [10], this material seems well suited to the technical demands of buried mask.

Figure 2 shows three SEM micrographs of the surface of the quartzplate after e-beam patterning and re-

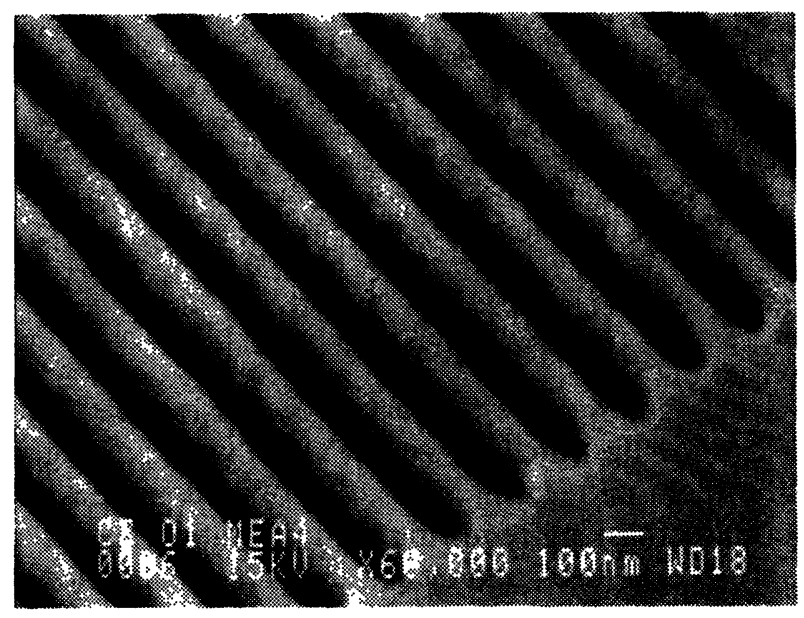

a)

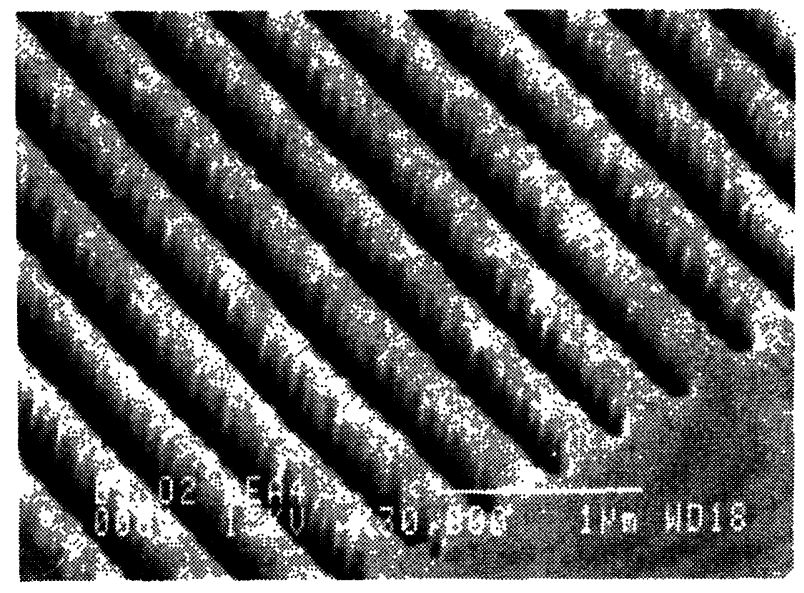

b)

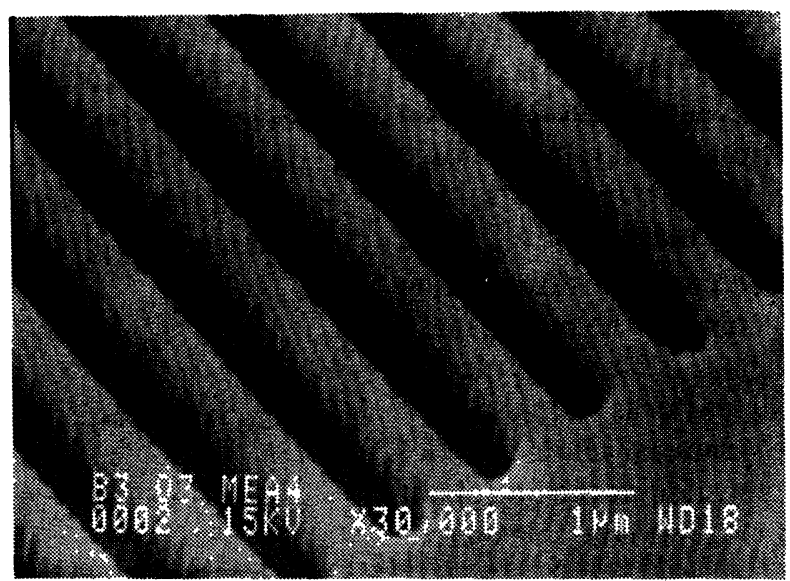

c)

Fig. 2. - SEM micrographs of the surface of the quartz plate after E-beam patterning, etching the glass and removal of $\mathrm{W}$ layer, but before filling the trenches. Width of the trenches : a) $0.1, \mathrm{~b}) 0.2$ and c) $0.3 \mu \mathrm{m}$. Depth of the trenches : $0.15 \mu \mathrm{m}$. Resist : PMMA $0.2 \mu \mathrm{m}$ thick. E-beam exposures : Cambridge EBMF 6 at $20 \mathrm{keV}$. Plasma RIE etching : SF6 and CHF3. 
moval of the $\mathrm{W}$ layer. High resolution gratings $(0.1,0.2$ and $0.3 \mu \mathrm{m}$ lines and spaces) are obtained. Nevertheless it can be seen on the micrographs that the straightness of the line edges is not perfect. This is of course related to the natural width $(0.1 \mu \mathrm{m})$ of the electron beam of the pattern generator (Cambridge EBMF 6), but in the same way demonstrates the high resolution potential of the system.

2.2 FILLING THE TRENCHES. - According to the principle of the buried mask, the holes created are now to be filled with an absorbing material. Naturally, $\mathrm{Cr}$ is a potential choice. However considering the problems of undesired light diffusion and reflection created along the pattern edges, it would be preferable to choose materials whose interface is less reflective, like $\mathrm{W}$ or even dyed polymers. Of course other molecules could be selected, provided they absorb the exposure light sufficiently and can be set in the holes. Selective deposition, planarisation and lift-off appear to be the three main techniques for filling in the holes. This

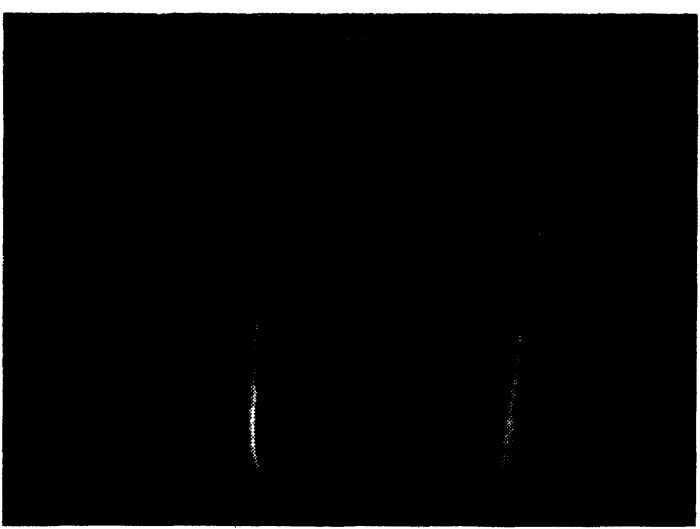

a)

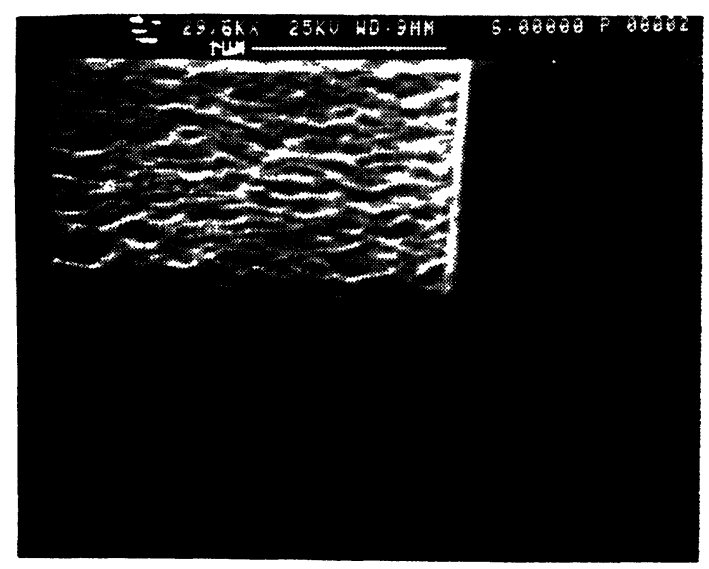

c) paper shows results obtained by means of the last two techniques.

2.2.1 Planarisation. - Tungsten appears to be a good candidate due to its different properties. The

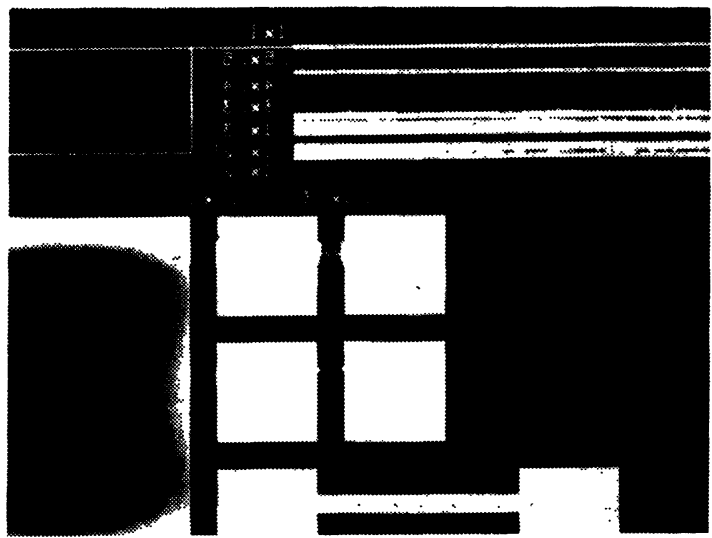

Fig. 3. - Optical micrograph of $100 \times 100 \mu \mathrm{m}^{2}$ areas filled by the planarised $W$ layer. The $500 \times 500 \mu \mathrm{m}^{2}$ areas are not filled.

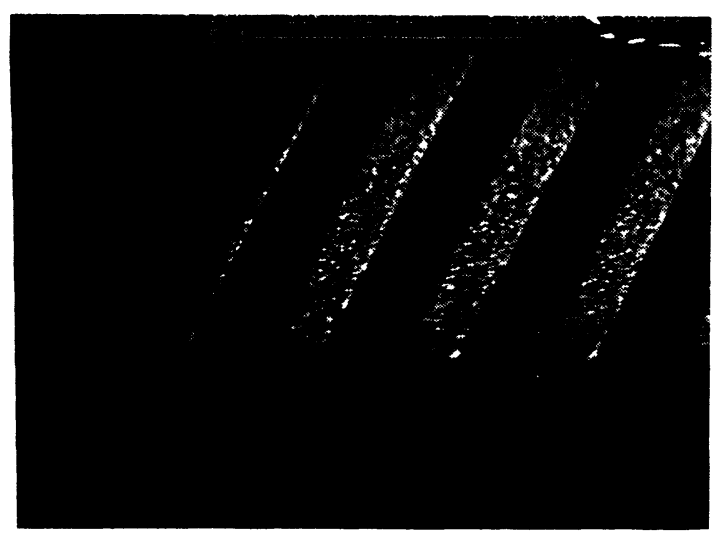

b)

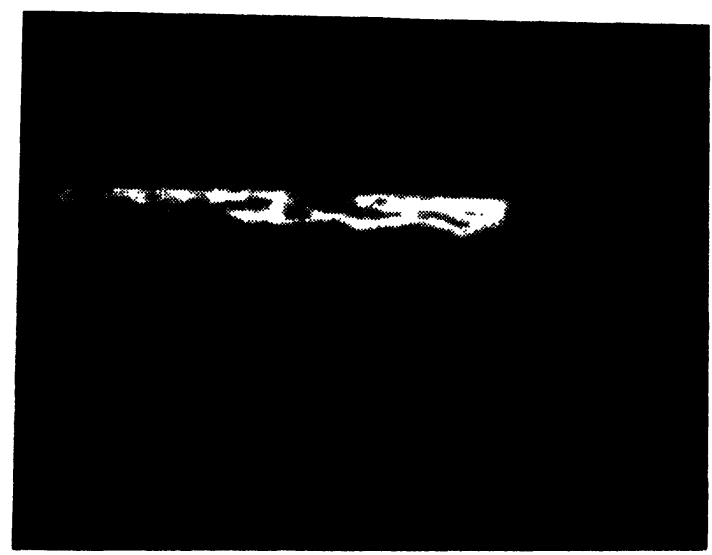

d)

Fig. 4. - SEM micrographs of a) HPR/PMMA bilevel pattern and a $1.5 \mu \mathrm{m}$ width trench etched within an oxyde layer. Whole topography is then capped by a directionally deposited W layer. After "lift-off" of the resist : b) c) and d) trenches of $\mathrm{SiO}_{2}$ filled with $150 \mathrm{~nm}$ of $W$. 
process consists of photoresist coating $(1.8 \mu \mathrm{m}$ thick HPR 204), flood exposing $\left(300 \mathrm{~mJ} / \mathrm{cm}^{2}\right), 250^{\circ} \mathrm{C}$ post exposure baking and plasma etching under conditions which etch $\mathrm{W}$ and resist at the same rate [11]. No roughness has been measured over the clear areas on the mask, even when the etching process includes an overetch time of several minutes. The SEM micrograph printed in figure 3 shows that areas as large as $100 \times 100 \mu \mathrm{m}^{2}$ are filled by the planarised layer. This process is well suited to filling in very small features, leading to highly resoluted gratings.

2.2.2 Lift-off. - On the other hand, the lift off technique is well suited to filling in wide areas, but may be limited in providing high resolution and a good step coverage. Figure 4a shows SEM micrographs of an HPR/PMMA bilevel pattern [19] and a $150 \mathrm{~nm}$ deep trench etched into the glass. The whole topography is then capped by a W layer deposited by a directional sputtering technique. By immersing the structure for a few seconds in a solution of potassium ferricyanide and potash, the photoresist patterns are removed but the trenches remain filled with a $150 \mathrm{~nm}$ W layer, as illustrated in the figure $4 \mathrm{~b}, \mathrm{c}, \mathrm{d}$.

2.2.3 Planarisation and lift off. - Pei-lin Pei et al. [12] have proposed an improved lift off process which does not require overhang resist profiles and therefore leads to submicronic geometries. It represents a combination of the planarisation and lift off techniques and could be applied to the case of the buried mask.

\section{Expected properties of the buried mask.}

According to the concept of buried mask, several interesting properties can be expected. Among them :

3.1 HARD WEARING. - The absorbent patterns, as schematically represented in figure $1 \mathrm{~b}$, are embedded in the trenches of the plate. For this reason they are protected against the shear deformation and tearing up which take place when the plate suffers from solid contact (hard or vacuum contact exposure, brush cleaning,...).

3.2 EASINEsS OF ClEANing. - On the top surface of conventional masks the pattern edges form $100 \mathrm{~nm}$ high barriers of $\mathrm{Cr}$ which may catch on or retain the small particles. In contrast, in the case of the buried mask, the flatness of the top surface allows the particles to move during cleaning of the plate. Furthermore if the trenches are not completely filled by the absorbent material it is possible that the small particles will settle in the small depression above the pattern. In this case the particle is not considered as a defect as it is located just in the shadow of the absorbent feature.
3.3 High RESOLUTION. - As indicated by D. Shernock [13], in the future dry etching will definitely prevail in the maskmaking industry. For the $\mathrm{W}$ etch process only a very thin layer of a poorly etch resistant resist is needed ( $0.2 \mu \mathrm{m}$ of PMMA), reducing thus the proximity effects and giving consequently rise to highly resoluted gratings. In contrast, the $\mathrm{Cr}$ etch process requires chlorinated gases and oxygen must be added to form a volatile product. If not, a polymer forms and coats the plate. For this reason the selectivity of the $\mathrm{Cr}$ etch process is very bad and the resist edge undergoes erosion resulting in unacceptable line edge roughness and poor linewidth control. Therefore any future evolution in $\mathrm{Cr}$ photoplate seems limited [14] in terms of : ultimate resolution, linewidth control, and throughput

Considering these three fundamental characteristics, the buried mask appears to be an alternative solution to the relief mask as the etch step of the $\mathrm{Cr}$ layer is removed and replaced either by the etch of a $30 \mathrm{~nm}$ thick $\mathrm{W}$ layer or by that of $150 \mathrm{~nm}$ into the bulky $\mathrm{SiO}_{2}$. These two etch processes, well controlled by IC manufacturers, are most desirable mainly because the usual novolak based resists present a better resistance to fluorinated plasmas than to oxygen-chlorinated plasmas. As an illustration, table I compares the dimensions of lines to that of spaces as measured on a W buried mask and shows that the W/quartz etching process is likely to yield a satisfactorily dimensional control.

Table I. - Comparison of the dimensions of lines to that of spaces as measured on a W/quartz buried mask for various exposure doses.

\begin{tabular}{|lllllll|}
\hline \multicolumn{7}{|c|}{ Dose of e - beam exposure $\left(\mu \mathrm{Cb} / \mathrm{cm}^{2}\right)$} \\
\hline$L / S$ & 230 & 245 & 260 & 275 & 290 & 305 \\
$0.2 / 0.2$ & 0.72 & 0.90 & 1 & 1.33 & 1.43 & 2.33 \\
$0.3 / 0.3$ & 0.86 & 0.86 & 1 & 1.20 & 1.37 & 1.55 \\
$0.4 / 0.4$ & 0.76 & 0.89 & 1 & 1.03 & 1.11 & 1.30 \\
$0.5 / 0.5$ & 0.88 & 0.80 & 1 & 1.11 & 1.04 & 1.54 \\
$0.6 / 0.6$ & 0.93 & 0.85 & 1 & 1.04 & 1.09 & 1.20 \\
$0.7 / 0.7$ & 0.94 & 0.94 & 0.97 & 1 & 1.16 & 1.35 \\
\hline
\end{tabular}

3.4 DEFECT INSPECTION. - As defect detection systems become more efficient at locating smaller defects, they necessarily become sensitive to pattern anomalies which could be ignored for larger defect detection sizes [15]. According to this point of view, the reduced line edge roughness and better linewid th control of the buried mask concept should lead to an increase in the efficiency of the defect inspection systems.

3.5 OPTICAL DIMENSIONAL METROLOGY. - Concerning the measurements of the size of the Cr patterns it has been theoretically and experimentally demonstrated [16] that the major contribution to the total un- 
certainty is the slope of the edge on the mask. Whereas the slopes of the $\mathrm{Cr}$ feature are measured at between 60 and $70^{\circ}[13,16]$, the trenche edges of the buried mask are almost vertical as previously shown in figure 2. Consequently it is expected that the optical dimensional metrology is easier to handle with a buried mask than with a relief mask.

3.6 REFLECTION. - A main cause of linewidth variations in optical lithography is the light refracted off the sidewall of the absorbent patterns. Physically, the reflection is not a specific property of a material but results as an intrinsic property of the interface between two materials. Formally, materials commonly known as "reflective" present an interface with the air which is capable of reflecting light. If only the case of the normal reflection from medium 1 onto medium 2 is considered, the ratio of the intensity of the reflected light to that of the incident light is given by the complex indices $N_{1}=n_{1}-i k_{1}$ and $N_{2}=n_{2}-i k_{2}$ according to the equation (1):

$$
R=\left\{\left(n_{1}-n_{2}\right)^{2}+k_{2}^{2}\right\} /\left\{\left(n_{1}+n_{2}\right)^{2}+k_{2}^{2}\right\}
$$

Medium 2 is the absorbent material. Medium 1 is glass in the case of the buried mask $\left(n_{1}=1.45, k_{1}=0\right)$ and air in the case of the relief mask $\left(n_{1}=1, k_{1}=0\right)$. The value of $k_{2}$ is related to the absorbing coefficient $\beta$ at the wavelength $L$ by equation (2):

$$
\beta=2 \pi k / L
$$

Let us consider various absorbing materials : $\mathrm{Al}$, $\mathrm{Cr}, \mathrm{W}$ and two heavily dyed resists (resist $\mathrm{A}$ absorbs $99 \%$ of the light through $0.2 \mu \mathrm{m}, \mathrm{B}$ through $0.1 \mu \mathrm{m})$. The values of $R$ for these five materials in the case of the buried mask and the relief mask are listed in tables II. It is to be concluded that a) the concept of buried mask can significantly reduce the rate of the undesirable reflected light in optical lithography and b) that heavily dyed polymers should be regarded as potential absorbents for filling in the buried mask.

Table II. - Ratio of the intensity of the reflected light to that of the incident light for different materials.

$\begin{array}{lcccc}\text { Absorbent material } & n_{2} & k_{2} & R \text { (Buried mask) } & R \text { (relief mask) } \\ \text { Resist A } & 1.7 & 0.685 & 5 \% & \\ \text { Resist B } & 1.7 & 1.370 & 16 \% & \\ \text { Al } & 0.6 & 5.380 & 89 \% & 92 \% \\ \text { Cr } & 1.8 & 4.080 & 62 \% & 77 \% \\ \text { W } & 3.31 & 2.491 & 33 \% & 46 \%\end{array}$

\section{Results : image transfer.}

4.1 COPY OF MASKS. - Copying of the mask is usually performed by contact printing. This limits the number of prints that can be produced from a master as each contact printing step is likely to introduce contact induced defects in the mask [17]. It is though that a buried mask may limit the probability of the introduction of defects due to wear and tear. The buried mask technique enables a copy of a master to be made, in an identical or reversed tone, depending on whether a negative or positive resist is used.

By spinning a photoresist layer (2:1 solution of HPR 204 and cellosolve acetate) over a quartz photoplate (600 $\mathrm{nm}$ thick) and exposing it through the master mask in a vacuum contact mode $\left(7.8 \mathrm{~s} ., 8.2 \mathrm{~mW} / \mathrm{cm}^{2}\right)$ with a $310 \mathrm{~nm}$ wavelength, patterns as small as $0.35 \mu \mathrm{m}$ are produced. They are then transferred into the glass substrate by plasma etching and filled with $\mathrm{W}$ (see Fig. 5).

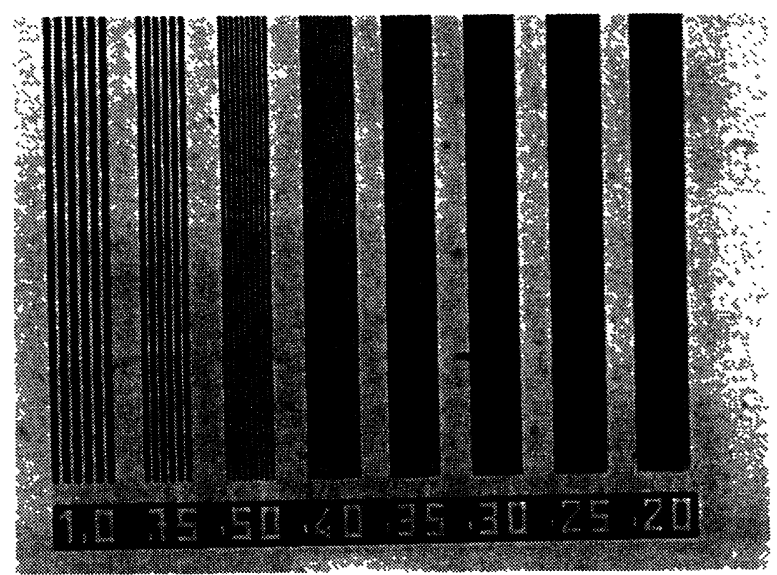

a)

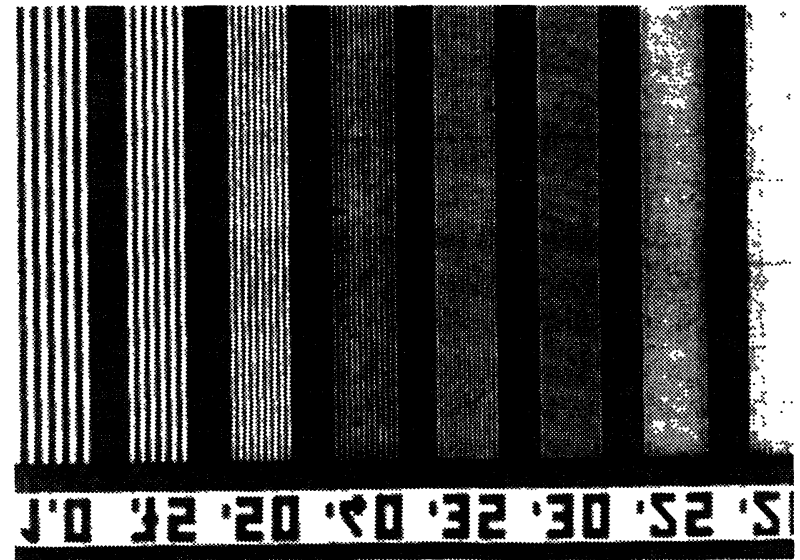

b)

Fig. 5. - Comparison of a highly resolved DUV photomask and a copy of it, achieved according to the buried mask concept. Main steps were ; $30 \mathrm{~nm}$ W deposition, $400 \mathrm{~nm}$ PMMA deposition, E-beam exposure, development, $\mathrm{W}$ etching by SF6 plasma, stripping the resist, $200 \mathrm{~nm}$ etching of the quartz plate by CHF3 RIE plasma, W deposition, coating of a sacrificial novolac layer, planarisation by SF6 + 02 plasma etching.

4.2 $\mathrm{SiO}_{2} / \mathrm{Si}$ SUBSTRATE. - Some experiments of vacuum contact printing in a DUV photoresist on silicon wafers are carried out. The trenches into the mask 

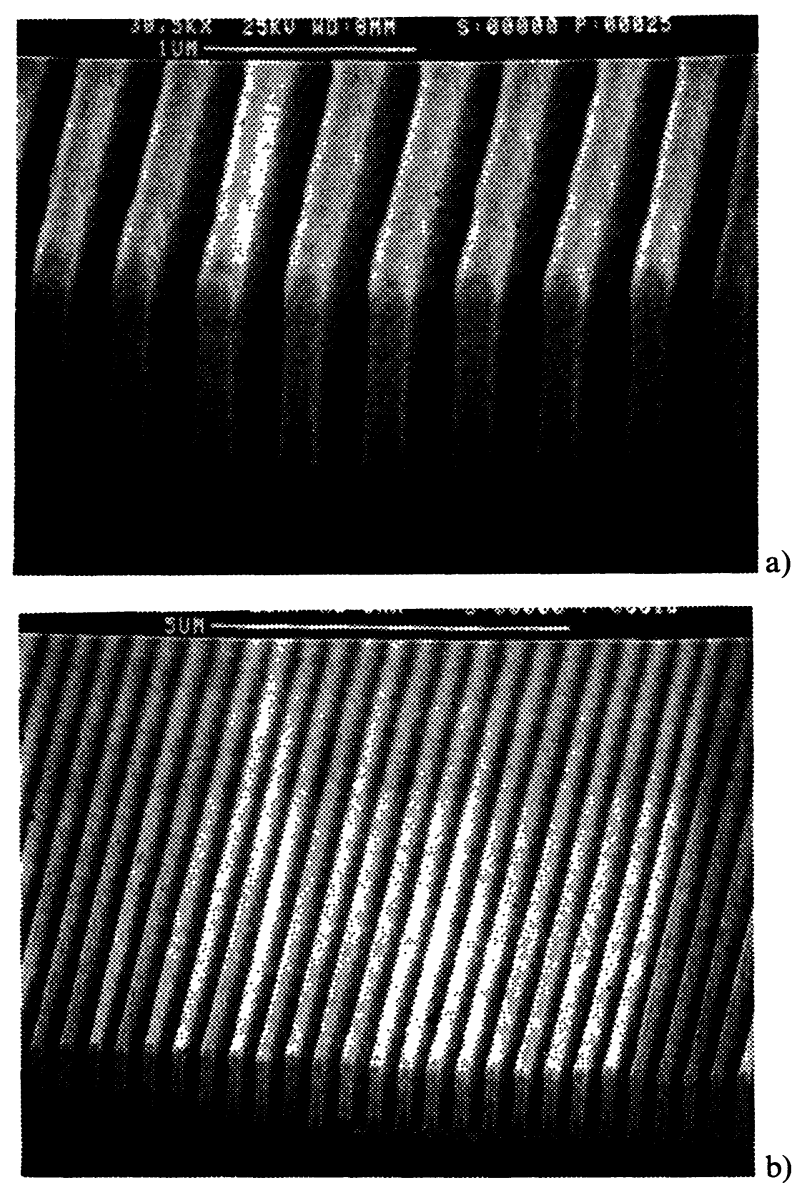

Fig. 6. - Lines $0.2 \mu \mathrm{m}$ and spaces $0.2 \mu \mathrm{m}$. Vacuum contact printing mode using the buried mask. Bilevel technique RIE O2: $0.15 \mu \mathrm{m}$ silicon containing resist over $1.2 \mu \mathrm{m}$ novolak resist over oxide. Deposited energy : $35 \mathrm{~mJ} / \mathrm{cm}^{2}$. Wavelength exposure : $220 \mathrm{~nm}$.

are filled with W. As an example of image transfer from the buried mask into a resist layer figure 6 shows highly resoluted features : $0.2 \mu \mathrm{m}$ lines and space gratings are obtained in a bilevel resist system.

4.3 MASK WITHOUT ABSORBENT. - Experiments are also conducted by the mean of an unfilled mask (mask of phase). The mask is only made of quartz. The

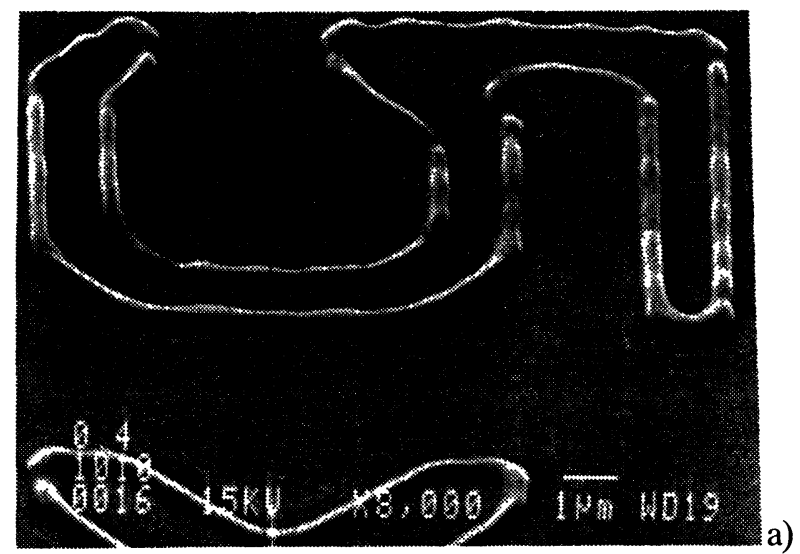

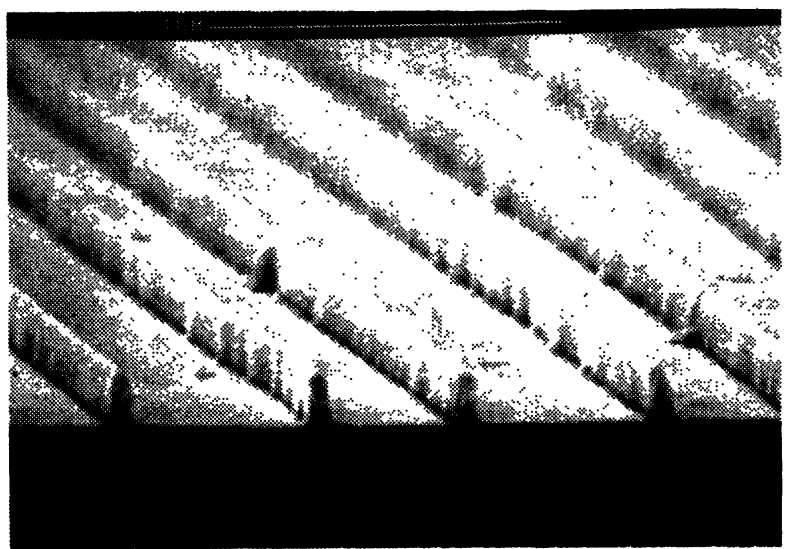

b)

Fig. 7. - Mask without absorbent material. Trenches were etched but not filled. The edges of the patterns are transfered into a $0.5 \mu \mu$ thick PMIPK DUV resist : ODUR 1010. The width of the lines on the silicon wafer is roughly $0.15 \mu \mathrm{m}$.

trenches are not filled by an absorbent material. Each edge of the trench diffracts and diffuses light, giving rise to a small line about $0.15 \mu \mathrm{m}$ in width on the wafer. Diffusion due to the roughness of the etched surface, depends of the conditions of etching the trenches. This technique allows to obtain very small gratings. Illustrations of this effect are given in figure 7.

\section{Conclusions.}

To date, all efforts to reduce the critical dimensions in integrated circuits have concentrated on light sources, optical systems, resists or sequence processes, but not really on the conception of masks. The recent progresse in photomasks has only concerned the fabrication technology of masks (dry etching of features, $\mathrm{MoSi}_{2}$ layer,...) or the development of a method of compensation for systematic errors resulting from the photolithographic process [1]. This paper proposes an elaborate lithography on glass mask which could be regarded as a new departure in the manufacture of masks for sub- $0.5 \mu \mathrm{m}$ optical lithography.

DUV exposures through buried masks allows high resolution patterns to be obtained, similar to those obtained by direct writing E-beam exposure. The buried mask will therefore be of great utility for laboratories involved in nanometric structures.

The feasibility of fabrication of the buried mask has been demonstrated by using well known and reliable IC technologies. In spite of an increased number of steps during fabrication the buried mask could well lead to overall improvements. The numerous expected properties could benefit both $1 \mathrm{X}$ and $5 \mathrm{X}$ reduction lithography [18]. 


\section{Acknowledgements.}

We would like to thank all our colleagues who helped at special stages for fabricating the burried mask : J. Torres, J. Palleau, N. Bourhila and D. Laviale for metal deposition, C. Desplat and N. Guillard for their fruitful support in defect inspection, J. P. Gonchond for his help in low voltage SEM observations, H. Martin for his useful discussion in metrology. Acknowledgements are due to M. Pichot and D. Henry for their valuable discussions. We are also grateful to M. Timmins for the reading of manuscript.

References

[1] DunBraCK S. K., Masks for sub-0,5 $\mu \mathrm{m}$ optical lithography, SPIE Sta Clara Symp. Lithogr. 922 (1988) 3.

[2] The limits of Photomasking, Solid State Technol 141 (1988).

[3] BurggraAF P., The skills behind 'Perfect' Masks, Semicond. Int. (aug. 1988) P. 76.

[4] Hirokane, Europ. Patent, EP 0234547 A2 published 02/09/1987 bulletin 87/36.

[5] Patent Abstract of Japan, vol. 10, $\mathrm{n}^{\circ} 220$ (p- 482), $31 / 07 / 1986$ \& JP -A-61 56 349, 22/03/1986.

[6] Patent Abstract of Japan, vol. 7, n 60 (p- 182) \{1205\}, 12/03/1983 \& JP-A- 57207 256, 18/12/1982.

[7] Patent Abstract of Japan, vol. 8, $\mathrm{n}^{\circ} 175$ (p- 294) \{1612\}, 11/08/1984, \& JP-A- 5968 744, 18/04/1984 ; Patent Abstract of Japan, vol. 8, $n^{\circ}$ 97, (P-272) $\{1534\}$, 08/05/1984 ; \& JP-A-59 9659, 19/01/1984.

[8] PANABIĖRe J. P., Brevet français $N^{\circ} 8714156$ du 0810 1987.

[9] Francou J. M., Panabière et Weill A., Brevets français $\mathrm{N}^{\circ} 8804107$ du $29031988, \mathrm{~N}^{\circ} 8817040$ du 19121988 et $N^{\circ} 8817041$ du 19121988.

[10] ZINSMEISTER G.J., Quartz-the ultimate material for optical lithography ?, SPIE 333 (1982) 40.
[11] SAIA R. J., GOROWTTZ B., WOODRUFF D. and BROWN D. M., Plasma etching methods for the formation of planarized tungsten plugs used in multilevel VLSI metallisations, J. Electrochem. Soc. 135-4 (1988) 936.

[12] Pei P. L., Diamand Y. S. and Oldham W., A high resolution lift off technology for VLSI interconnections, Third Int. VLSI Multilevel Interconnection Conf. (1986).

[13] SHERNOCK D., The limits of maskmaking : dry etching, Solid State Technol (may 1988) p. 152.

[14] NOVEMBRE T., The limits of maskmaking : resists, Solid State Technol. (May 1988). p. 149

[15] REYNOLDS J. A., The limits of maskmaking : defect inspection, Solid State Technol (may 1988) p. 148.

[16] NYYSSONEN D., Optical dimensional metrology for IC fabrication, SPIE Sta Clara symp. microlithogr., Tutorial 11 (1988).

[17] MEYERHOFER D. and MITCHELL J., Proximity printing of chrome mask, Pol Eng. Sci. 23 (1983) 18.

[18] WILEY J. N., The printability of 5X reticle submicron defects, Microlithogr. News, 15 (nov. 1988).

[19] Weill A., DechenauX E., Paniez P., Amblard G., Bilevel system HPR/PMMA, SPIE Proc. 811 (1987) 162. 